\title{
SOMOS TODOS MORTAIS: O CORONAVÍRUS E A NATUREZA ABERTA DA HISTÓRIA ${ }^{1}$ WE ARE ALL MORTALS: THE CORONAVÍRUS AND THE OPEN NATURE OF HISTORY
}

\author{
Rita Laura SEGATO \\ Universidade de Brasília (UnB), Brasília, Brasil \\ ritalsegato@gmail.com \\ https://orcid.org/0000-0003-3676-5542
}

A lista completa com informações dos autores está no final do artigo

\begin{abstract}
RESUMO
No presente ensaio Rita Segato mobiliza um conjunto de interpretações sobre o possível significado da pandemia do novo coronavírus, em que ele é compreendido como: 1) catalisador de um colapso da ilusão neoliberal; 2) justificativa para a imposição de um estado de exceção; 3) "solução final"; 4) acessório de uma abordagem bélica de estabelecimento de novos inimigos; 5) sintoma da forma insustentável como tratamos o meio ambiente; e 6) arauto da necessidade de uma politicidade em chave feminina. Todas elas, entretanto, estariam fundadas numa vontade de onipotência: a de enquadrar a história em um rumo previsível. Diante da incomunicabilidade deste evento do presente, ela defende como prioridade a abertura para o imprevisível, e a proteção da vida no aqui e agora.
\end{abstract}

PALAVRAS-CHAVE: Pandemia. Futuro. América Latina.

\begin{abstract}
In this essay Rita Segato mobilizes a set of interpretations about the possible meaning of the new coronavirus pandemic, in which it is understood as: 1) a catalyst for a collapse of the neoliberal illusion; 2) a justification for the imposition of a state of exception; 3) a "final solution"; 4) an accessory of a warlike approach to the establishment of new enemies; 5) a symptom of the unsustainable way we treat the environment; and 6) a herald of the need for a feminine key politicity. All of them, however, would be based on a will of omnipotence: that of framing history in a predictable course. Faced with the incommunicability of this present event, she defends as a priority the openness to the unpredictable, and the protection of life in the here and now.
\end{abstract}

KEYWORDS: Pandemic. Future. Latin America.

\footnotetext{
1 Tradução realizada por Loren Marie Vituri Berbert (email: lorenberbert@gmail.com; orcid: https://orcid.org/0000-0002-8083-9505) doutoranda em Sociologia e Ciência Política pela Universidade Federal de Santa Catarina (UFSC) e Renato Bradbury de Oliveira (email: renato.brad@hotmail.com; orcid: https://orcid.org/0000-0002-7034-1703) doutorando em Literatura pela Universidade Federal de Santa Catarina (UFSC). Publicação original em espanhol: SEGATO, Rita Laura. Todos somos mortales: el coronavirus y la naturaleza abierta de la historia. In: KASSIR, Alessandra et al. Alerta Global. Políticas, movimentos sociales y futuros en disputa en tempos de pandemia. Editado por Breno Bringel e Geoffrey Pleyers. Ciudad Autónoma de Buenos Aires: CLACSO; Lima: ALAS; 2020.
} 
Que a pandemia ilumine a diferença entre o que importa e o que não importa.

\section{O QUE É, O QUE NÃO É E AO QUE NOS CONDUZ A PANDEMIA²}

Um número significativo de textos tem circulado por estes dias, muitos deles escritos por autores influentes. Eles procuram dar conta de dois aspectos distintos da pandemia que nos aflige. Um grupo faz apostas sobre qual pode ter sido a origem do vírus, dividindo-se entre aquelas que aderem à teoria da conspiração e as outras que, sem necessariamente o saber, dão continuidade ao que Marx chamava de "ruptura metabólica" ou desequilíbrio da relação entre os seres humanos com a natureza.

Me ocuparei aqui de outro conjunto de interpretações, que dizem respeito ao significado e ao uso futuro da pandemia. Cada um deles é derivado de, e tem como pressuposto um projeto político e um sistema de valores que defende.

De minha parte, vejo a Covid-19 como Ernesto Laclau viu a figura de Perón na política argentina: um "significante vazio" ao qual diversos projetos políticos direcionaram sua rede discursiva. Também a vejo como um evento que dá origem a um "efeito Rashomon", evocando aqui a forma pela qual as ciências sociais se apropriaram do tema do clássico filme de Kurosawa: um mesmo crime relatado a partir de quatro perspectivas de interesses diferentes. Mas sobretudo a vejo como aquela situação que Lacan chamou de "irrupção do real", o imaginário que captura nossa visão de mundo, ou anteparo, através do qual filtramos as entidades que farão parte de nossa percepção em um fino tecido que nos envolve. Além dele se encontra o "real", para usar o termo de Lacan: a natureza tal como é, incluindo a nossa própria natureza.

O vírus não é outra coisa senão um evento de desdobramento deste outro plano, a História Natural, a marcha aleatória da natureza, seus desdobramentos contingentes, seu movimento à deriva. Os organismos se consolidam, duram e desaparecem. Nossa espécie também seguirá esse destino incerto ou, com sorte improvável, terá a longevidade da barata, o que será difícil, pois a barata se caracteriza por precisar de pouco. É importante aceitar a ideia de que mesmo que este vírus tenha sido resultado da manipulação humana no laboratório ou, como certamente é, uma consequência da forma abusiva com a qual a espécie vem tratando seu meio ambiente, de toda forma se trataria de um evento da

2 Uma versão inicial desse texto foi publicada em Grimson (2020). 
natureza. Por quê? Porque nós somos parte dessa mesma natureza e, ainda que sejamos capazes, enquanto espécie, de manipular micro-organismos e provocar o advento de uma nova era como é o Antropoceno, temos nosso lugar lá, somos parte desta cena que chamamos "natureza". Nossa interação bioquímica pertence e desempenha um papel numa cena dentro do grande ninho que habitamos, mesmo que o pensamento ocidental nos tenha pressionado a nos retirar daquela posição integrada, interdependente e dependente. Pensar assim não é fácil para nós, porque estamos dentro da lógica cartesiana do sujeito-objeto, da cabeça-corpo, da mente-res extensa. A reificação e a externalização da vida é nosso mal ${ }^{3}$.

Ao realizar essa manobra, o pensamento ocidental cancela duas moléstias. Uma delas é a temporalidade da vida, com sua inerente falta de controle e o limite que ela coloca à tentativa de administrá-la. O tempo, que não é outra coisa senão o tempo dos organismos, da própria Terra como um grande organismo, e da própria espécie como parte deste grande útero terrestre, desafia a onipotência do Ocidente, sua obsessão por administrar os eventos, o que chamei em outro lugar como sua neurose de controle. A outra obsessão do pensamento colonial-moderno ocidental, é a de nos colocar, como espécie, numa posição de onipotência: de quem sabe e pode manipular a vida, a manobra cartesiana de formular a res-extensa, a vida coisa, e nos atirar para fora da mesma. Por isso, frente a esta pandemia, temos a oportunidade de nos salvar cognitivamente desta armadilha e compreender que, seja qual for o efeito de nossa interferência, o vírus que está nos adoecendo é, de todo modo, um evento natural deste acontecer sinuoso e imprevisível que é o tempo. E é assim porque resulta de uma interação dentro do reino da natureza, de cuja cena somos parte. O salto de um vírus do animal ao humano deve ser lido desta forma, que nos recoloca na posição de ser parte do mundo natural com suas indeterminações, que muitas vezes acreditamos tê-las dominado. Toda uma disponibilidade distinta para a vida e para o inevitável da morte surge de uma consciência que aceita ser uma parte subordinada da ordem natural. A exterioridade cartesiana, longe de ser universal, carrega um vício de leitura próprio ao Ocidente e têm consequências.

O outro grande tema é o do futuro, vinculado também à dimensão anárquica do tempo. As três imagens de que falo me permitem supor que uma grande desorientação tenha ocorrido no mundo diante desta rara praga de conduta arcaica. Diante dessa desorientação, atribuo a ela três imagens: a ausência de um significado e intencionalidade

\footnotetext{
${ }^{3}$ Agradeço à minha filha Jocelina Laura de Carvalho Segato pelas incontáveis horas de conversa sobre os erros cognitivos e epistemológicos do especismo.
} 
própria, sua provocação Rashomon e sua realidade radical e independente de nossas apostas, que me permitem discorrer sobre uma futura batalha pela imposição de uma ordem a essa desorientação. E toda aposta teleológica esconde um discurso de supremacia moral, e todo discurso de supremacia moral tem uma vocação autoritária. Quem terá então a permissão de narrá-lo no futuro, para usar a expressão de Edward Said, ou quem deterá o direito de narrar, usando aqui as palavras de Homi Bhabha? Então, essas três figuras teóricas nos permitem prever uma batalha para decidir qual rede de significações, quais discursos e quais relatos serão capazes de apreender o evento que nos desafia, para instalar assim as políticas que darão forma ao mundo porvir. Entretanto, conforme já argumentei, a única utopia que sobreviveu aos sucessivos fracassos "revolucionários" em seu intento de reorientar o caminho dos povos é a absoluta imprevisibilidade do futuro: nunca sabemos onde ou como soprará o vento da história. O que nos resta é fazer nosso papel de acordo com nossas convicções e responsabilidades.

Temos visto diversos prenúncios de conflitos prestes a acontecer por estes dias, e este texto, também, está inevitavelmente incluso. Muitas redes de significado foram dispostas para capturar o tempo da natureza. Logo de início, testemunhamos a divergência entre dois grandes analistas tais como Slavoj Žižek e Byung-Chul Han: utopia e distopia em confronto, ao mesmo tempo como presságios. A partir daí, centenas de atribuições de significado circularam em muitos textos, mas o vírus as ultrapassa na sua incerteza e na desorientação na qual submeteu a humanidade. É muito importante considerar isso, pois nos leva à abertura da história, à sua imprevisibilidade e à aceitação dos limites implacáveis impostos à nossa capacidade de controlá-la, ordená-la. O vírus é a prova da vitalidade e da constante transformação da vida, do seu carácter irrefreável. Demonstra a vitalidade da natureza, conosco dentro dela. Mostrou uma realidade que nos excede e supera todo o voluntarismo. O Ocidente é assim confrontado com o que constitui a dificuldade suprema do mundo colonial-moderno, porque a meta por excelência do projeto histórico eurocêntrico é a dominação, a reificação e o controle da vida. Encurralar e bloquear todos os imprevistos, toda a improvisação, tem sido a sua intenção e o seu relativo triunfo progressivo.

Este vírus e todos os que o antecederam e os que virão depois, apresentam uma liberdade que abala ainda mais do que a própria morte a esta proposta civilizadora. Uma liberdade desconhecida. Assim, a ordem do dia só poderia ser recuar para "tirar a água do peixe", deixar o novo ser sem hospedeiro, até que a curva de sua periculosidade mude de direção e/ou uma vacina surja do papel que desempenhamos nesta grande cena: a cena ambiental. O que sabemos funciona, mas mais do que um controle indica uma "adaptação", 
uma flexibilidade e maleabilidade dos comportamentos, e uma capacidade de resposta que faz parte do mesmo drama, dos quais fazemos parte. Grande lição que este minúsculo ser dá ao Ocidente.

Difícil e camuflado no discurso da mídia foi o incontestável impacto inicial do vírus, porque o seu aparecimento em cena foi francamente democrático. Ele atacou em primeiro lugar e com grande força as duas maiores potências do mundo e a rica e confortável Europa. Neste momento, está envergonhando a Big Apple e a todo o chamado "mundo desenvolvido", ao demonstrar que lhes falta o que pareciam ter: segurança para a sua gente e capacidade de cuidados gerais e em grande escala para os seus habitantes. Ele atacou nobres, políticos de alto nível e empresários de poderosas corporações. Fez surpreendentes baixas entre as elites cosmopolitas. Diante da própria lente midiática, mostrou ao mundo que, sem dúvida, todos nós somos mortais. Comportou-se como um migrante a quem não se pode colocar barreiras. Levou o próprio Henry Kissinger a falar sobre o fim da hegemonia estadunidense.

É possível dizer que, pelo menos durante algum tempo, o vírus, um acontecimento da natureza, deu uma lição de democracia. Na América Latina, enquanto isso, é possível adivinhar um terror expectante e apenas suspeito, uma meia verdade sobre o que sabemos que pode acontecer quando o vírus finalmente derrubar a fronteira que protege a inclusão da exclusão.

O que acontecerá quando ele "cruzar massivamente os trilhos" e fazer sua entrada, com toda a força, incontrolável, entre os pobres? Até hoje, em nosso continente, devido à quarentena, a exclusão penaliza aqueles que vivem rigorosamente para o dia, devido à sua necessidade de rendimentos diários, mas não é na sua área que a peste tem sido sentida mais fortemente neste momento. O que acontecerá quando ele acertar em cheio os espaços superpopulosos? Isso ainda não vimos. Talvez caiba aqui uma digressão sobre o caso particular de Guayaquil. Visitei essa cidade e os seus arredores numa ocasião, e acredito que devido à sua extensa área portuária onde os barcos de pesca e também de contrabandistas e traficantes atracam, é possível dizer que existe ali uma grande população que, sendo pobre, é também cosmopolita. Essa rara conjunção entre pobreza e cosmopolitismo é o que penso estar por detrás da vulnerabilidade gritante dessa cidade.

Voltando à futurologia praticada por autores notáveis, as tentativas de capturá-lo têm sido, até agora, pelo menos as seguintes:

- O vírus tornará possível o colapso da ilusão neoliberal e o abandono da acumulação egoísta, porque sem solidariedade e sem estados provedores não iremos nos salvar. 
Sem um Estado que garanta a proteção e a entrega de recursos a quem menos tem, não será possível continuar a vida. A posição, neste caso, é a de que compreenderemos que é necessário colocar a acumulação à disposição das pessoas que precisam dela para sobreviver, e que os governantes serão levados a desobedecer ao preceito fundamental no qual o capitalismo se apoia.

- A segunda previsão que circula por aí poderia ser descrita como "agambeniana" e é indicada pela ficção científica distópica. Estaríamos adentrando num laboratório experimental em grande escala que permitirá que a população mundial seja vigiada com meios de controle digital e inteligência artificial a partir de novas tecnologias infalíveis. Tudo será informado sobre cada um dos viventes e a ameaça de um estado de exceção de magnitude desconhecida irá assolar a humanidade.

- Governantes como Trump e Bolsonaro parecem aderir, sem o enunciar reflexivamente, a um terceiro prognóstico, relacionado com o não dito sobre o massacre esperado quando o vírus atravessar a grande fronteira com os "cantegriles" $\mathrm{e}$ as favelas. Um subtexto do seu discurso e ação parece acenar para o extermínio do excedente do sistema econômico, o curvar-se à lei de sobrevivência do mais forte, do mais apto. Uma perspectiva neomalthusiana e um neodarwinismo social estão aqui presentes, uma ideologia totalitária - na definição de ideologia de Hannah Arendt - cujo valor afirma que qualquer pessoa que não esteja adaptada à sobrevivência em determinadas circunstâncias, ou que possa prejudicar o projeto nacional tal como definido pela perspectiva no poder, deve perecer. O vírus, visto a partir dessa ideologia, enquadra-se na "solução final" característica do totalitarismo: o que não serve, no sentido de que não presta serviço a um ideário, não deve viver. Esta posição, que é ideológica e responde ao projeto político de um setor de interesses, não deve ser confundida com uma abordagem como a da Alemanha, por exemplo, que diverge da estratégia da quarentena rigorosa e da extinção do vírus a partir da restrição absoluta de hospedeiros humanos, e permite a circulação de pessoas apostando no declínio natural do poder infeccioso do vírus mediante o aumento da imunidade humana. Esta última abordagem não é a mesma que a da proposta do neodarwinismo social porque os estados proponentes, como a Alemanha e a Suécia, têm uma maior oferta de atendimento e equipamento médico

${ }^{4}$ NT [Nota dos tradutores]: Como são chamados no Uruguai os assentamentos informais formados por um conjunto de habitações precárias. 
para reduzir a letalidade do vírus. Ainda assim, já surgiram dúvidas sobre a aposta no desenvolvimento natural da imunidade humana, que sem dúvida colocará em risco a vida de muita gente, e os países que adotaram essa estratégia a estão abandonando.

- A quarta interpretação adere à importância de uma abordagem bélica e vai em direção a uma atitude fascista. Assim, se treina para agir com base na existência de um inimigo. A paranoia em relação a ele sobe à cabeça. Toda política construída sobre a presunção da existência de um inimigo comum tende necessariamente ao fascismo. A inimizade e o belicismo se convertem na razão de ser da política. O vírus serve às forças de segurança para agir dentro dessa perspectiva, e lógicas punitivas e de extermínio são desencadeadas. Uma parte da população, cujo perfil na política e na cidadania tem essas características, tem se enquadrado hoje nessa leitura da pandemia. Há uma quantidade de exemplos de expressões de animosidade e agressividade extrema contra vizinhos que trabalham em hospitais, sejam médicos ou enfermeiros, contra pessoas que chegaram do exterior, ou pessoas que estejam doentes. A fúria e o ódio referente a qualquer pessoa associada à doença se espalham entre os setores reacionários da sociedade, que pretendem, no futuro, impor essa ordem social frente ao que definem como "ameaça pública": doentes, migrantes, não-brancos, delinquentes, imorais e etc.

- A quinta previsão é que, no fim, haverá de persuadir e de se impor a todos a ideia de que a Terra, sob qualquer dos nomes que recebe, nos terá demonstrado seu limite, e ficará provado que a exploração industrial da natureza nos leva em uma direção suicida. Ricos e pobres, segundo os que pensam assim, teremos aprendido o que os povos indígenas nos tem repetido tantas vezes: "Não temos a terra, Ela é que nos têm".

- Uma sexta postura é a de que o vírus impôs uma perspectiva feminina sobre o mundo: reatar os nós da vida comunal com sua lei de reciprocidade e ajuda mútua, adentrar ao "projeto histórico dos vínculos" com seu objetivo idiossincrático de felicidade e realização, recuperar o aspecto político do doméstico, domesticalizar a gestão, fazer com que administrar seja equivalente a cuidar, e que o cuidado seja sua principal tarefa. É a isso que se tem chamado atualmente de um "Estado materno", como distinto daquele Estado patriarcal, burocrático, distante e colonial do qual nossa história nos acostumou a desconfiar. 


\section{PERTURBAÇÃO DA ONIPOTÊNCIA E LUCIDEZ DA PRECARIEDADE}

Sejamos honestos, todas essas apostas podem ser perfeitamente convincentes, dependendo de qual seja o projeto histórico ao qual se adere, e dos interesses que nos representam. Todas são igualmente interessantes e inteligentes, mas todas são onipotentes, no sentido de que pretendem, de antemão, vencer na roleta do tempo. Todas elas sofrem da neurose de controle do Ocidente, em seu esforço de enquadrar a história em um rumo previsível. Mostram a arraigada incapacidade de estar, evocando aqui inevitavelmente o resgate da potência do tempo em seu fluxo, empreendido por nosso filósofo Rodolfo Kush, quando substituiu o ser heideggeriano pelo estar andino.

Problemas que já existiam se mostram exacerbados e mais visíveis, rasgando a superfície que antes os barravam. O projeto histórico do capital, e sua estrutura manifesta no que tenho chamado "projeto histórico das coisas" como oposto ao "projeto histórico dos vínculos", havia bloqueado com eficiência a consciência da finitude. Era preciso colocar a morte em um planeta distante. No entanto, hoje temos um funeral midiático, são centenas de caixões impudicamente expostos. É possível que isso desvie nosso desejo em outra direção, além daquela de costume: que importância poderiam ter as marcas frente à presença da Morte na vizinhança? Melhor nos acomodarmos. Enfim...

Além disso, as pragas são sempre bíblicas, pedagógicas, instrutivas. De repente é possível nos perguntarmos se a ordem institucional e econômica a que respondíamos não eram fictícias, se o universo que habitamos já não adoecia de uma precariedade insustentável. Mais do que pelas mortes que ocasiona, pois já vimos muitos óbitos e mortandades que não pararam o mundo, é a perplexidade, o descontrole e a imprevisibilidade que a criatura microscópica introduziu que perturba a credibilidade do sistema. Por exemplo, o vírus tem demonstrado que é possível mudar a realidade praticamente com uma "canetada" presidencial. Há aqui uma pedagogia cidadã: nada é imutável, tudo pode ser alterado, bastando vontade política. Em relação à gestão da vida, constatamos que é possível transformar o mundo em um grande laboratório no qual se realiza um experimento grandioso. É isso que tira o chão dos donos do planeta.

Que agora ninguém venha dizer que "não é possível tentar outras formas de se estar em sociedade" ou outras formas de administrar a riqueza: é possível parar a produção, e é possível parar o comércio. Estamos presenciando um fenomenal ato de desobediência, sem poder adivinhar qual será a rota de saída. O mundo se transformou em um vasto 
laboratório, onde um experimento parece ser capaz de reinventar a realidade. Se revela, de repente, que o capital não é uma máquina que independe da vontade política. Muito pelo contrário. Estamos agora diante da evidência que os donos da riqueza e seus administradores sempre tentaram esconder: a chave da economia é política, e as leis do capital não são as leis da natureza. Estamos diante de um Estado de exceção inusitado que, inversamente, apertou o botão que suspende a operação da grande máquina que confundíamos com o ordenamento divino. Uma pseudo ordem divina, uma farsa cuja metáfora perfeita é o famoso bezerro de ouro bíblico, o falso deus que desviou o povo de Israel em sua travessia à Canaã: uma grande praga que veio colocar um falso deus no lugar do verdadeiro. O capital é o falso deus, a Mãe Terra é o verdadeiro. E esses são os mitos na grande episteme da espécie: sempre pautam nossa leitura do presente.

\section{O AQUI E AGORA: A TRAMA DA RECIPROCIDADE COMUNAL RECUPERADA}

Proteger a vida, cuidar dela no aqui e agora, da forma como for possível, em um presente absoluto, é tudo o que importa. Não é assim com os prognósticos e com as declarações de princípio e intenção moral, pois como já argumentei em outro lugar, nesta fase apocalíptica do capital, o discurso de persuasão moral se tornou inócuo frente à pedagogia da crueldade, que inoculou em nossos corações e consciências o antídoto super eficaz que suspende a percepção empática do sofrimento alheio. Além disso, as diretrizes para o futuro baseadas em um suposto ideal generalizado de bem são arriscadas: frente a qualquer falha no preceito que estabelecemos, a construção inteira se partirá, e a qualquer decepção nos parecerá desabar a estrutura que cuidadosamente tínhamos edificado. Trabalhar com previsão é algo perigoso, pois não temos dados claros nem sobre o presente e nem sobre o futuro. Não conhecemos com precisão aquilo que nos ameaça. O que importa é aprender a estar, a se cuidar na medida do possível, e a lidar com o chão em movimento sob nossos pés. Sugeri em outro lugar que uma politicidade em chave feminina se adapta melhor a esse tipo de contingência, na qual salvar a vida é tudo o que importa.

Em mais de um texto apresentei o Estado como a última fase da história do patriarcado. Disse que quando a tarefa política masculina deixa de ser uma entre duas tarefas políticas, e o espaço onde ela é executada deixa de ser um entre dois espaços - o 
público e o doméstico, cada um com seu próprio estilo de gestão - para converter-se em uma esfera pública abrangente (e agora única), de todo discurso que se pretenda dotado de politicidade, ou seja, capaz de impactar no destino coletivo, nesse momento, a posição das mulheres, atualmente reféns na cápsula da família nuclear, se desvincula da qualidade marginal, de resto, expropriada de toda politicidade. No entanto, me ocorre que a abordagem albertiana -- sua maneira de falar conosco -- é, ao menos nesta circunstância, uma gestão doméstica da nação. "Materna", tenho dito publicamente, porque o materno e o paterno independem do corpo em que se depositam, como nos ensinou há muito tempo a útil e vilipendiada categoria "gênero", grande formulação do feminismo que nos permitiu desessencializar, desbiologizar papéis e sexualidades. Alberto Fernández pede que nos unamos, e isso gera uma experiência incomum em nosso país. Gera comunidade, ao nos pedir que deixemos de lado a discórdia e tentemos começar de novo para enfrentar o desconhecido, diz que vai nos proteger e considerar as necessidades materiais em suas desigualdades. É por isso que tenho dito que parece encarnar um estado maternal, uma gestão doméstica, como uma inovação. Não posso deixar de recordar aqui as duas noções de pátria a que o maravilhoso ensaio de Jean Améry, Cuánta patria necesita un hombre, faz referência: a pátria patriarcal, bélica, defensiva, cercada, e a pátria maternal, hospitaleira, anfitriã. As línguas nórdicas têm duas palavras diferentes para elas: vaterland ou fatherland para uma, e heimat, homeland, ou país natal, para a outra. É imprescindível destacar este acontecimento, a diferença albertiana, porque ao teorizar não somente descrevemos os eventos, mas também os prescrevemos, os fazemos ser, lhes outorgamos realidade, os encorajamos de alguma forma. Temos que identificar e nomear as novidades que aparecem na desconhecida cena do presente.

Mais que uma fantasia de futuro, devemos prestar atenção ao que há de fato, às propostas e práticas que emergem, o que as pessoas estão concretamente fazendo e inventando. O que está acontecendo aqui e agora, ao nosso redor, entre nós. Novamente: a politicidade em chave feminina, como disse outras vezes, é tópica e não utópica, prática e não burocrática. Nessa vigília, formas de sustentar a vida que estavam se extinguindo vão lentamente se revigorando. Vamos nos dando conta de que ao menos uma parte da capacidade de subsistência tem que ficar necessariamente nas mãos das próprias pessoas. Ressurge em nosso país a memória de 2001. Nossa própria Odisseia no espaço, infelizmente arquivada. Experimentamos um sentimento de perda muito grande quando percebemos que, a partir do momento em que o Estado retoma de forma eficaz as rédeas da economia nacional, e o período de grande carência é superado, toda aquela economia 
popular se desintegra. Na fome e na intempérie de 2001 surgiram estruturas coletivas, 0 individualismo recuou e o país passou por uma mutação que é possível perceber até hoje. Mas, quando o problema das necessidades materiais imediatas se resolveu, nada foi feito para promover a permanência dessas estruturas operativas que tinham sido criadas.

Tenho defendido que o bom Estado é um Estado que restitui o âmbito comunitário, protetor da produção e do mercado local e regional, capaz de estimular um caminho anfíbio: não poderá abdicar de um mercado global porque provem de seus dividendos os recursos para suas políticas públicas, mas também não deve abandonar a autossustentabilidade das comunidades, a soberania alimentar e o mercado local enraizado que, como no caso presente, volta a tornar-se crucial para a sobrevivência. Um bom Estado transita entre os dois caminhos e protege o mais frágil, para que seus saberes, seus circuitos próprios de negócios, suas tecnologias de sociabilidade e seus produtos não se percam, muito menos sua autonomia. Hoje vemos novamente como ressurgem ao nosso redor as hortinhas nas varandas, corredores, galerias e pátios, a troca de seus produtos entre vizinhas; o governo propõe as quarentenas comunitárias, em bairros que se fecham como comunas; os coletivos retomam seu papel, fazem coletas, se organizam para que as pessoas comam, e minhas vizinhas de San Telmo ${ }^{5}$ me perguntam todos os dias, pela internet, se preciso de algo. Não esqueçamos dos milhões de hindus "walking home", um lugar que ninguém jamais deveria ser obrigado a deixar. Vemos a ansiedade pelo retorno à terra em toda parte, e temos a obrigação de entender esse movimento visceral, atávico, de voltar para casa.

\section{EPÍLOGO}

O problema que resta é: como garantir que essa experiência fique registrada nos discursos do tempo pós-pandemia e permaneça audível para, dessa forma, evitar que seja refeita a fantasia de normalidade e inalterabilidade que nos capturava? Como reter a experiência de um desejo que, ao menos durante esse intervalo, se encaminhou livremente em direção à novas formas de satisfação e realização? Haverá forças habilidosas, muito bem instruídas, estudando o tema para encerrar essa memória, bani-la, deixá-la bem vedada, para garantir dessa forma a volta a uma "normalidade" que a pandemia teria

\footnotetext{
${ }^{5} \mathrm{NT}$ : Bairro de Buenos Aires.
} 


\section{REFERÊNCIAS}

GRIMSON, A (Org.). El futuro después del COVID-19. Buenos Aires: Presidencia de la Nación, 2020. p. 76-88.

\section{NOTAS}

\section{TÍTULO DA OBRA}

SOMOS TODOS MORTAIS: O CORONAVÍRUS E A NATUREZA ABERTA DA HISTÓRIA

\section{Rita Laura Segato}

Professora emérita da Universidade de Brasília, e professora da Universidade Nacional de San Martín, na Argentina. Seus trabalhos sobre gênero nas comunidades indígenas e latino-americanas, violência de gênero, e as relações entre gênero, racismo e colonialidade são referências inevitáveis. Autora de vários livros, entre os quais se destacam Las estructuras elementales de la violencia (2003 e 2013), La Nación y sus Otros (2007) e La guerra contra las mujeres (2018).

Universidade de Brasília (UnB), Brasília, Brasil

ritalsegato@gmail.com

https://orcid.org/0000-0003-3676-5542

\section{LICENÇA DE USO}

Os autores cedem à Em Tese os direitos exclusivos de primeira publicação, com o trabalho simultaneamente licenciado sob a Licença Creative Commons Attribution 4.0 Internacional (CC BY). Estra licença permite que terceiros remixem, adaptem e criem a partir do trabalho publicado, atribuindo o devido crédito de autoria e publicação inicial neste periódico. Os autores têm autorização para assumir contratos adicionais separadamente, para distribuição não exclusiva da versão do trabalho publicada neste periódico (ex.: publicar em repositório institucional, em site pessoal, publicar uma tradução, ou como capítulo de livro), com reconhecimento de autoria e publicação inicial neste periódico.

\section{PUBLISHER}

Universidade Federal de Santa Catarina. Programa de Pós-Graduação em Sociologia Política. Publicado no Portal de Periódicos UFSC. As ideias expressadas neste artigo são de responsabilidade de seus autores, não representando, necessariamente, a opinião dos editores ou da universidade.

\section{HISTÓRICO}

Recebido em: 19 de janeiro de 2021.

Aprovado em: 20 de janeiro de 2021. 